\title{
Successful Dual-Patch Closure of a Fistula between the Right Pulmonary Artery and the Left Atrium
}

\author{
Abhishek Shrinivas Joshi, Balaji Dattatray Aironi \\ Department of Cardiovascular and Thoracic Surgery, Seth Gordhandas Sunderdas Medical College and King Edward VII Memorial Hospital, Mumbai, India
}

\section{ARTICLE INFO}

Received May 6, 2020

Revised June 28, 2020

Accepted July 1, 2020

Corresponding author

Abhishek Shrinivas Joshi

Tel 91-9820326126; 91-224107429

E-mail abhishekjoshi@kem.edu

ORCID

https://orcid.org/0000-0001-9893-1556

\begin{abstract}
A fistula between the right pulmonary artery and the left atrium is a very rare congenital anomaly, for which there is no definitive embryogenetic explanation. Patients present with cyanosis or clubbing, and the treatment strategy is to close the fistula, which can be done by an open surgical technique or by percutaneous intervention. Although rare, this condition should be considered in the differential diagnosis when evaluating a patient with central cyanosis.
\end{abstract}

Keywords: Anomaly, Cyanosis, Fistula

\section{Case report}

A fistulous connection between the right pulmonary artery (RPA) and the left atrium (LA), although rare, is a condition that cannot be neglected [1]. The largest collective case review by Chowdhury et al. [2] included 59 cases. This entity is also hardly mentioned in current textbooks of cardiology and cardiac surgery. Hence, the exact incidence of this rare condition has not been determined. The majority of cases are congenital, although traumatic etiology has been implied in a couple of cases. The usual presenting complaints and signs in patients with this condition are dyspnea on exertion, central cyanosis, decreased arterial oxygen saturation, and clubbing. The modalities used to diagnose this condition include 2-dimensional echocardiography, computed tomography (CT) scans, and angiography [3]. This anomaly has been classified into 4 types, and the type of fistula dictates the treatment approach. Although catheter-guided closure of the fistula has been recently proposed as a less invasive technique, numerous other factors are relevant when deciding upon the treatment approach for this condition [4]. It is always best to adopt a case-directed, individualized approach for the treatment of RPA-LA fistula. The mortality rate of this condition has decreased in recent years. Herein, we describe a case of RPA-to-LA fistula in a 32-year-old male patient.

A 32-year-old male farmer presented with complaints of grade II dyspnea on exertion for the last 8 years and pedal edema. He also gave a history of hospital admission for symptoms of severe headache and fever with chills. On examination, the patient's vital parameters were normal; he had grade 3 clubbing, central symmetrical cyanosis, and arterial oxygen saturation of $70 \%$. An ejection systolic murmur could be heard over the left second and third parasternal areas. A chest X-ray showed cardiomegaly and a wide carinal angle, and an electrocardiogram was suggestive of left atrial enlargement. There was early contrast filling of the LA on contrast echocardiography. The patient underwent a cardiac CT scan, which showed a fistula between the RPA and the LA (Fig. 1A). Aneurysmal dilatation of the left atrial appendage was also noted. Angiography was done to denote the course of the fistula from the RPA to the LA (Fig. 1B). Contrast injection clearly showed the opening in the LA. Individual pressures were not calculated; however, the patient's oxygen saturation increased to $96 \%$ upon complete occlusion of the right pulmonary ostium of the fistula. The patient was classified as having a type 1 communication and surgery was planned. The patient underwent surgery under cardiopulmonary bypass with moderate hypothermia using Del NIdo cardioplegia. Intraoperatively, the $3-\mathrm{cm}$-long fistula was found to arise 
from the RPA and communicate with the roof of the LA. The RPA was opened and the opening of the fistulous communication, which measured around $1.5 \mathrm{~cm} \times 1.5 \mathrm{~cm}$, could be easily seen at the inferior side of the RPA (Fig. 2A). The LA was entered via a trans-septal approach through the right atrium (RA). The opening in the roof of the LA was readily noted, and measured around $2 \mathrm{~cm} \times 2$ $\mathrm{cm}$ (Fig. 2C). We decided to perform a double-patch closure of the fistula instead of the more routine ligation or single-patch closure, as the fistula was thin-walled. Using 2 different patches also served as a safety mechanism for preventing air embolism during the postoperative period. The RPA opening was closed with a Dacron patch (Sauvage Filamentous Dacron; Bard, Tempe, AZ, USA) using interrupted polypropylene 6-0 sutures, and the LA opening was closed with a pericardial patch using continuous polypro-
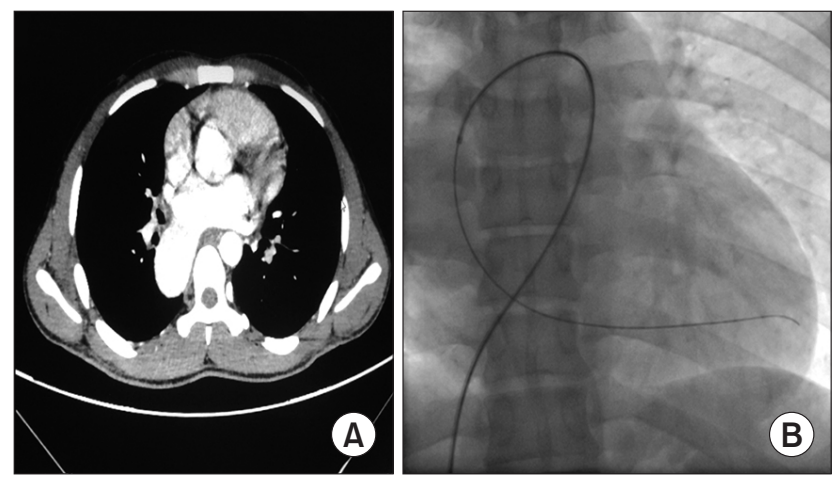

Fig. 1. (A) Cardiac computed tomography demonstrating filling of the left atrium and pulmonary bifurcation. (B) Catheter course from the inferior vena cava to the right atrium, right ventricle, pulmonary artery, right pulmonary artery, left atrium, and left ventricle. pylene 5-0 sutures after allowing the fistula to fill with blood (Fig. 2B, D). The interatrial septum and RA were closed and the patient was weaned off bypass. The total bypass time was 156 minutes and the cross-clamp time for the procedure was 124 minutes. The chest was closed primarily. Postoperatively, arterial oxygen saturation was $100 \%$. The patient had an uneventful postoperative course and was discharged on postoperative day 6 . After 2 months, another CT scan and 2-dimensional echocardiography showed no evidence of any fistulous communication. The patient is currently symptom-free.

The patient provided written informed consent for publication of the clinical details and images.

\section{Discussion}

A fistula between the RPA and the LA is a rare cause of cyanosis in adult patients. It is difficult to diagnose this condition based only on a clinical history and routine 2-dimensional echocardiography. Additional investigations, namely contrast echocardiography and CT, are needed to delineate such fistulous tracts precisely. This condition was classified into 3 types by de Souza e Silva et al. [5], and a fourth type was later added by Ohara et al. [6]. Hence, there are 4 major types of these fistulae and every type has a distinct line of management. Type 1 is an anomalous connection connecting the posterior aspect of the proximal RPA into the LA with normal pulmonary venous connection. Type 2 is a persistent and supernumerary branch of the pulmonary artery, which establishes an abnormal connection with the LA. In type 3, all pulmonary veins drain into an aneurysmal pouch between the RPA and the LA.
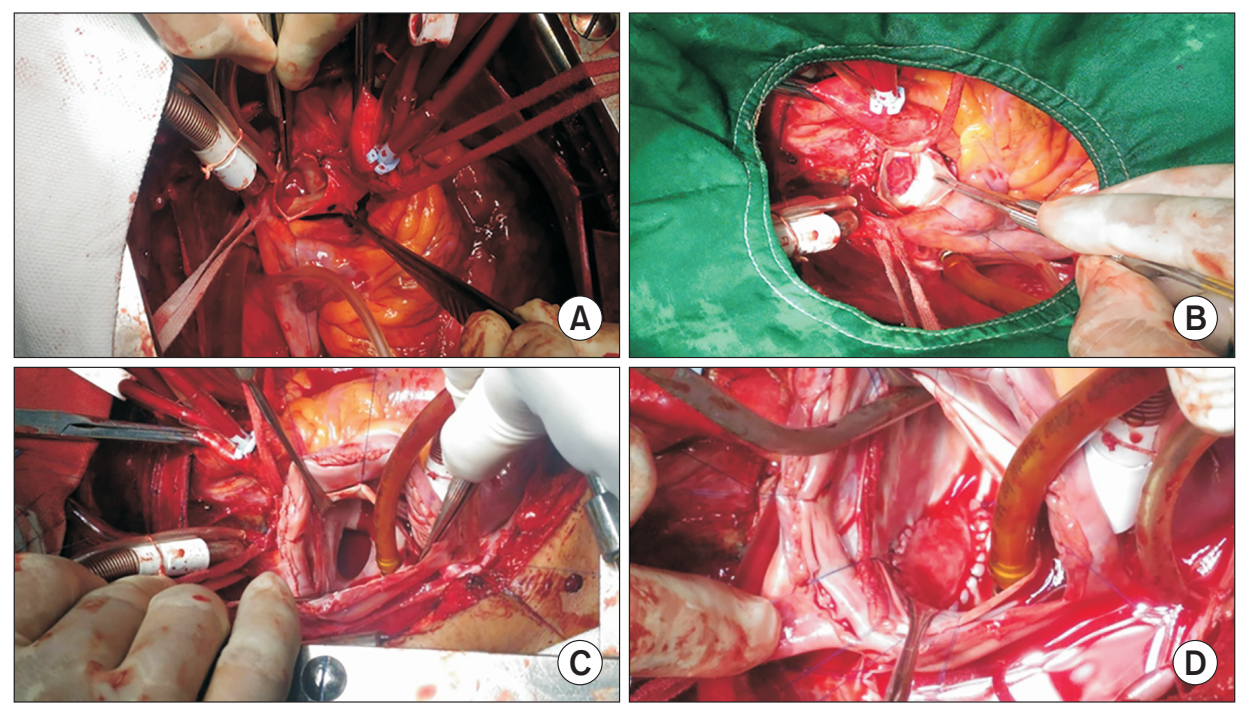

Fig. 2. (A) Opening in the RPA. (B) Dacron patch closure of the RPA opening. (C) Opening in the LA. (D) Pericardial patch closure of the LA opening. RPA, right pulmonary artery; LA, left atrium. 
In type 4, a very proximal pulmonary arteriovenous fistula joins the LA, such that the right pulmonary veins drain into the fistula and the left pulmonary veins drain into the LA directly. Even though this condition can be tackled by either vascular intervention or open surgery, it is best to plan the treatment on a patient-specific basis. It is necessary to treat this condition as early as possible upon diagnosis. Median sternotomy is a safe approach and closure of both ends using a patch is a safe method for the treatment of an RPA-LA fistula, as is simple division and ligation.

In conclusion, this report highlights a rare case of cyanosis in an adult patient and describes the pathway of diagnosing this condition. Dual closure of the fistula from both ends by using a Dacron and pericardial patch under cardiopulmonary bypass is a safe and simple procedure to treat this condition that led to a good outcome.

\section{Conflict of interest}

No potential conflict of interest relevant to this article was reported.

\section{ORCID}

Abhishek Shrinivas Joshi: https://orcid.org/0000-0001-9893-1556
Balaji Dattatray Aironi: https://orcid.org/0000-0002-6223-5011

\section{References}

1. Muthialu N, Joshi S, Hoskote A, Bhole V. Rare cause of central cyanosis: right pulmonary artery to left atrial fistula. Interact Cardiovasc Thorac Surg 2016;23:839-40.

2. Chowdhury UK, Kothari SS, Airan B, Subramaniam KG, Venugopal P. Right pulmonary artery to left atrium communication. Ann Thorac Surg 2005;80:365-70.

3. Narula J, Choudhury M, Chowdhary UK, Kiran U. Pulmonary arterypulmonary vein fistula: contrast echocardiography using agitated saline for indirect evaluation of adequacy of surgical repair. J Perioper Echocardiogr 2014;2:61-4.

4. Benz DC, Burkhardt B, Quandt D, Stambach D, Knirsch W, Kretschmar O. Interventional closure of RPA-to-LA communication in an oligosymptomatic neonate. Eur J Pediatr 2014;173:1703-5.

5. De Souza e Silva NA, Giuliani ER, Ritter DG, Davis GD, Pluth JR. Communication between right pulmonary artery and left atrium. Am J Cardiol 1974;34:857-63.

6. Ohara H, Ito K, Kohguchi N, et al. Direct communication between the right pulmonary artery and the left atrium: a case report and review of the literature. J Thorac Cardiovasc Surg 1979;77:742-7. 